\title{
Ácidos Húmicos: sustrato natural empleado como tratamiento alternativo en la inhibición de la bacteria Helicobacter Pylori, aporte desde la docencia para una mejora en la calidad de vida
}

Humic Acid: natural substrate used as alternative therapy in inhibition of Helicobacter Pylori bacteria, contribution from the teaching for improvement in the quality of life

Jesús Álvaro Jiménez Montoya, Tatiana Sarmiento Monsalve, Julieth Vanegas García y Diana Vargas Oviedo

Universidad Distrital Francisco José de Caldas. jajimenez@udistrital.edu.co, jeymyta@gmail.com, julietapaulin@hotmail.com, didi028@gmail.com

\section{Resumen}

A través de la historia, las enfermedades han sido tratadas por compuestos naturales, dentro de los que están los Ácidos Húmicos (AH), biopolímeros que se encuentran en plantas, aguas estancadas y carbones de bajo rango. Estos sustratos poseen grupos funcionales que les atribuyen propiedades terapéuticas para el hombre.

Es así como esta investigación emplea los AH como tratamiento altemativo en la inhibición de la bacteria Helicobacter Pylori (H Pylori) "in vitro", a través de un diseño experimental que parte de la obtención de las muestras (generadas a partir de 7 biopsias gástricas antrales), las cuales fueron inoculadas, cultivadas (con condiciones optimas para su supervivencia) y tratadas con los sustratos del carbón, determinando las mejores condiciones para su enradicación. Los resultados evidencian que al autodavar los AH se reduce su contaminación por otros microorganismos sin alterar las propiedades inhibitorias de los mismos. El rango de concentraciones de los AH ideal para inhibir la bacteria esta entre 0.375\%-0.75\% (\%p/v) (realizado con prueba de difusión en disco).

De igual forma, estos sustratos fueron empleados en monoterapias y terapias duales (AH + Amoxicilina), demostrando que presentan mayor halo de inhibición al ser utilizados individualmente que en una terapia dual; esto se debe probablemente a que tanto los AH como el antibiótico ejercen el mismo efecto sobre la bacteria (irmumpiendo en la correcta formación de la pared celular), por lo que los AH se podrían considerar como un bactericida.

De acuerdo con los resultados obtenidos, los AH pueden ser empleados en monoterapias, al ejercer posiblemente una función antibiótica y a la vez reguladora del pH del medio en que sobrevive la bacteria. El efecto bactericida de los AH esta dado por la presencia de grupos funcionales que inhiben a la enzima ureasa, lo que impide la fijación y crecimiento de la bacteria, interviniendo como agentes activos que modifican reacciones bioquímicas(Humifu/vate $R x$ ).

Teniendo en cuenta lo anterior, la viabilidad de emplear los AH como tratamiento alternativo en la inhibición de la bacteria H. Pylori, radica en poder sustituir las terapias utilizadas actualmente, las cuales son a base de medicamentos sintéticos, mejorando la calidad de vida a fin de transformar la visión del profesional docente en la química, aportando a la sociedad en la solución de problemas reales, aplicando conocimientos científicos desde una perspectiva investigativa.

Palabras Claves

Ácidos Húmicos, Helicobacter Pylori, Carbón Leonardítico, monoterapia, terapia dual. 


\section{Abstract}

Over time, diseases have been treated by natural compounds, as humic acids (HA), biopolymers that are found in plants, stagnant water and low rank coals, these substrates have functional groups, which attributed therapeutic properties to man.Thus, this research uses the AH as an alternative treatment in the inhibition of the bacterium H. Pylori in vitro, through an experimental design that start with the collection of samples (generated from 7 gastric antral biopsies) that were inoculated, grown (with optimal conditions for their survival) and treated with the coal substrates, determining the best conditions for eradication, where the results show that autodaving the AH reduces contamination by other microorganisms without altering the inhibitory properties, using a HA concentration range between $0.375 \%-0.75 \%(\% \mathrm{w} / \mathrm{v})$ (performed with disk diffusion test).

Likewise, these substrates were used in mono and dual therapies (AH + Amoxicillin), demonstrating that HA provide a larger zone of inhibition when used individually than in dual therapy, this is probably due to both, HA and antibiotic have the same effect in the bacteria (breaking the correct formation of cell walls), so, HA could be considered as a bactericide. According to results, HA can be used as monotherapy, since it probably exerts an antibiotic effect and possibly a regulatory function of pH in the survival bacteria environmental. The HA bactericide effect is given by the presence of functional groups that inhibit the enzyme urease, which prevents the establishment and growth of the bacteria, working as active agents that modify biochemical reactions. (Humifulvate $\mathbf{R x}$ ).

In accordance with former, the vialibity of HA use as alternative therapy in the inhibition of the Helicobacter Pylori bacteria, is based in the substitution of currently used therapies, which are based on synthetic medicines, these natural substances for improving the quality life in order to transform the vision of professional teaching in chemistry, contributing to society in solving real problems, applying scientific knowledge from a research perspective.

\section{Keywords}

Humic Acids, Helicobacter Pylori, coal Leonardito, monotherapy, dual therapy.

\section{Introducción}

En la actualidad y como consecuencia de factores derivados de la globalización y la situación económica mundial, se desarrollan en el hombre enfermedades que estadísticamente crecen en forma exponencial causando padecimientos largos y dolorosos, y en muchos casos la muerte.

Algunas de estas enfermedades han sido tratadas por medios naturales desde que el hombre existe, desconociéndose el principio científico de su acción. Entre los tratamientos naturales que se realizan desde la antigüiedad, están los que se hacen con compuestos orgánicos de alto peso molecular extraídos de algunos suelos, los AH.

\section{Ácidos Húmicos}

Los Ácidos Húmicos son biopolímeros que se encuentran en suelos, plantas, aguas estancadas y carbones de bajo rango como turbas y lignitos, hallándose junto a otras sustancias húmicas como los ácidos Fúlvicos y las huminas.

Las propiedades de los AH se establecen con el origen y/o rango del carbón; estos son materiales de color oscuro, los auales forman macromoléculas con propiedades de polieléctrolito; difícilmente solubles en agua y en casi todos los disolventes no polares, asi mismo son solubles en $\mathrm{NaOH}$, dando un color oscuro intenso, el cual depende del grado de dispersión, que parece ser máximo a pH 8; precipitan bajo la acción de ácidos fuertes como el $\mathrm{HCl}$, pero no con ácidos débiles. Son insolubles en alcohol y en bromuro de acetilo, propiedad que sirve para sepáralos de la lignina 
y sus productos de transformación. Los AH se oxidan poco y son resistentes a los ataques biológicos haciéndose estables y permanentes en el suelo. (LEVI \& PINEDA, 1996)

De acuerdo a investigaciones realizadas, no existe una estructura única, sin embargo, entre su variada composición se han encontrado como productos de la oxidación derivados de fenoles y quinonas, ácidos benzolcarboxílicos, nitrogenados tanto cídicos (indol, pirimidina, purinas), como aminoácidos y alifáticos, ácidos orgánicos de bajo peso molecular (oxálico y maleico), además de flavonoides entre otros compuestos que posen grupos funcionales $\left(-\mathrm{OH},-\mathrm{COOH}, \mathrm{C}=\mathrm{O},-\mathrm{NH}_{2}\right)$, (KONONOVA, 1982). (Figura 1)

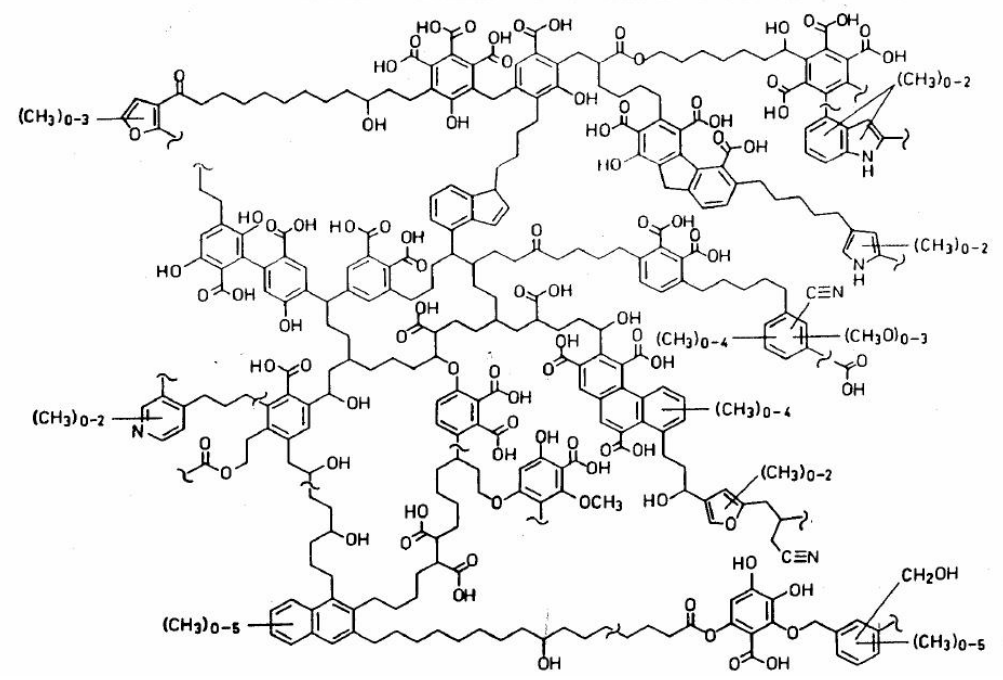

Figura 1. Estructura de la molécula de AH (KONONOVA, 1982)

Los AH al ser una molécula con diversidad de grupos funcionales, se les atribuyen propiedades químicas, física y biológica (probiótica y prebiótica) que los hacen ser útiles para el hombre, en las que están: la capacidad de complejación, ya que el papel que ejercen estos se basa en la nutrición de los organismos celulares como de plantas superiores (HOFFMANN, YOST, EISENREICH, \& MAIER, 1981), inhibidores de la enzima ureasa y de la nitrificación (MIKKELSEN $R, 2005$ ), precursores de síntesis 0 actividad, efecto en el metabolismo de los cultivos se nota en una mayor asimilación de dióxido de carbono, mayor síntesis de ATP, mayor respiración mitocondrial y actividad fotosintética (FOSAC, 2005), entre las propiedades quimicas se encuentra que los AH son capaces de complejar varios nutrientes, incrementar la disponibilidad de macronutrientes, como fósforo, y micronutrientes, especialmente cinc y hierro (MIKKELSEN $R$, 2005) y finalmente presentan la alta capacidad de intercambio catiónico.

Así mismo los AH se han caracterizado por tener un uso casero en los tratamientos de algunas enfermedades, atribuyéndole diversas propiedades terapéuticas, las cuales aun no han sido estudiadas ampliamente y aryo referente teórico es insuficiente, como lo es la utilización de los AH en diversas patologías tales como: gastritis, ulcera gástrica y duodenal, dermatitis, reumatismo, osteoporosis, enfermedades musculoesqueléticas, degenerativas, hepáticas, inflamaciones, cáncer, ulceras de la piel, entre otros. (HumicHealth.info).

Además de las anteriores patologías, investigaciones recientes han demostrado que los $\mathbf{A H}$ pueden ser un posible tratamiento para la enadicación de la bacteria $H . P y l o r i$, ya que al emplear estos sustratos se logra una inhibición de este tipo de bacterias "in vitrd", lo aual es estudiado no solo empíricamente en países tales como España, Alemania y Sudáfrica sino un estudio realizado en la Universidad Distrital Francisco José de Caldas. 
Helicobacter Pylori

La bacteria H.Pylories uno de los patógenos, que acarrea un problema global, ya que según los estudios realizados se estima que la mitad de la población mundial la padece, además de estar relacionada con un sin número de enfermedades gastrointestinales y posiblemente enfermedades cardiovasculares.

La bacteria H.Pylori es una bacteria Gram negativa, microaerofilica, no esporulada, tiene forma de un bastón curvado de 2.5 a $4 \mu \mathrm{m}$ de longitud y de 0.5 a $1 \mu \mathrm{m}$ de ancho, que coloniza la mucosa gástrica antral, (esta es una bacteria que vive exclusivamente en el estómago humano, espećficamente se posa en el antro parte inferior del estómago, siendo el único organismo capaz de sobrevivir en un ambiente extremadamente ácido), posee de tres a siete flagelos polares envainados en uno de sus extremos, es decir tiene flagelos múltiples y unipolares, lo cual produce una inflamación aguda y crónica denominada gastritis crónica activa, la infección es asociada a la ulcera pepitica. (SIERRA \& TORRES, 2001) (GÓMEZ, 1995).

Mecanismo de infección

Para entender como la H.Pylori, logra infectar y ocasionar enfermedades en el hombre existen autro pasos importantes 1. Colonización, la bacteria entra al huésped se adhiere a la superficie de la capa epitelial gástrica y se establece requiriendo factores que permiten que se dé el proceso, como lo es producir amonio a partir de la urea para neutralizar el ácido segregado por el estómago, ya que a pH bajos la colonización del estómago es difícil y el microorganismo debe protegerse del ácido presente 2. Escape al sistema inmune logrando una proliferación en el foco de la infección. 3. Daño directo al huésped. 4. Daño al huésped inducido por la respuesta inmune (CANOSA, 1980).

Para detectar la presencia de H.Pylori, "in vitro" se emplea una técnica de contraste o diferencial (GUEDEA FERNANDEZ, 2007), que al estar en contacto con esta bacteria Gram negativa se obtiene como resultado una coloración rosada, debido a que estas bacterias poseen una delgada capa de peptidoglicano que permita arrojar resultados positivos. Así mismo se emplean las pruebas de identificación denominadas ureasa, catalasa y oxidasa, las auales permiten diferenciar esta bacteria de otras Gram negativas, al poseer dentro de su estructura estas enzimas (Ureasa, oxidasa y catalasa).

Investigaciones han estudiado la inhibición de la bacteria H.Pylori, por medio de medicamentos, que cumplen distintas funciones en el tratamiento de la misma, es así como se encuentran compuestos de tipo antibiótico y no antibiótico, entre los que están:

Antibiotico: betalactamicos (Amoxicilina), (SIERRA \& TORRES, 2001), macrólidos (Eritromicina), Nitroimidazoles. (VALSECIA).

No antibioticos (encargados de nivelar el pH gástrico): Inhibidores de la bomba de protones (Omeprazol) , antagonistas de los receptores $\mathrm{H}_{2}$, Sales de Bismuto (SIERRA \& TORRES, 2001). Los anteriores medicamentos son empleados como base de las terapias que actualmente inhiben la bacteri H.Pylori, denominadas monoterapias, terapias duales y triples (figura 2) para la presente investigación se tomo como referencia la terapia dual Amoxicilina más Omeprazol, la cual presenta un alto porcentaje de sensibilidad. 


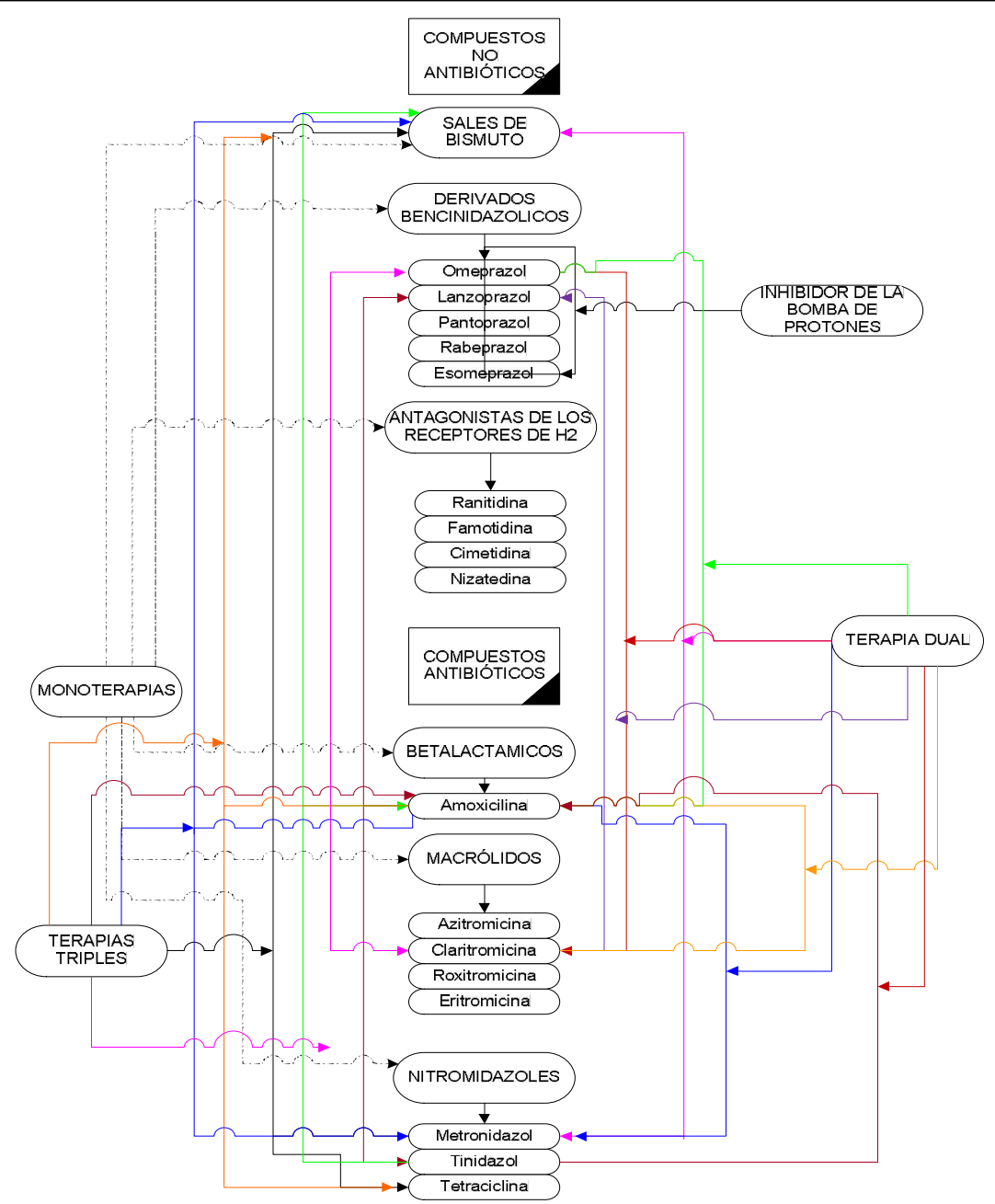

Figura 2. Diagrama de las terapias y medicamentos utilizados en la inhibición de la bacteria H. Pylori.

\section{Metodología}

El diseño metodológico parte de la caracterización del carbón Leonarditico colombiano del aual se extraen los AH, realizándose un análisis geográfico, próximo y último, lo que permite determinar propiedades como: humedad, cenizas, materia volátil, nitrógeno, cloro y azufre. Luego de ello se hizo una extracción de los AH a partir de sus propiedades físicas, por agitación constante, el cual consiste en una precipitación con ácido sulfúrico a un pH menor a 2, método estandarizado en la Universidad Distrital Francisco José de Caldas.

Debido a que los AH son moléculas complejas orgánicas extraídas del carbón de naturaleza muy particular y distinta entre sí, se realizó un estudio de este sustrato, teniendo mayor conocimiento de las características físicas y químicas, (análisis próximo y elemental) y determinar el comportamiento real de estas sustancias, en la inhibición de la bacteria H.Pylori (CONICET).

En cuanto al tratamiento de la bacteria H.Pylori con el empleo de los AH, se realiza un cultivo con siete biopsias de pacientes de sexos y edades diferentes, los auales presentaban síntomas relevantes de gastritis, (posiblemente generada por la bacteria H.pylori), para ello se tomaron muestras de mucosa gástrica antro pilórica, las cuales fueron transportadas en de caldo tioglicolato con glicerol al $\mathbf{2 0 \%}$ 
Antes de realizarse la inoculación de las muestras de las biopsias, se hizo una mezda (homogenización), solubilizándolas en solución fisiológica, generando una cepa nativa, la cual fue inoculada y sembrada en un medio no selectivo en agar BHI (Brain-Heart Infusion), con $7 \%$ de sangre de caballo, enriquecida con isovitalex en cajas de petri, llevando cada una de ellas a un periodo de incubación aproximado de 5 días, a una temperatura de $37^{\circ} \mathrm{C}$, humedad aproximada de $95 \%$ en condiciones de microaerobiosis (5-10\% de $\mathrm{CO}_{2}, 80-90 \%$ de $\left.\mathrm{N}_{2}\right)$, acompañado de un pH de 7.2 (Bruce 1997), en jarras anaerobias con sobres generadores GasPak, dándole las condiciones necesarias que aseguraran la supervivencia de la bacteria.

Al cabo del periodo de incubación se comprobó el desarrollo de tres masas visibles, denominadas colonias, las cuales fueron sometidas a sucesivas resiembras, según la Escala Mc Farland 2. Luego de evidenciar que los microorganismos crecieron, se procedió a colocar las terapias con AH esterilizados, para establecer las diferencias con los sustratos que no fueron sometidos a este proceso, es así como se administraron a los aultivos los tratamientos con AH esterilizados (autodavado por calor húmedo, $121^{\circ} \mathrm{C}$ y $15 \mathrm{Lb}$ de presión) y no esterilizados a concentraciones diferentes $(0.0625 \% \mathrm{p} / \mathrm{v}, 0.125 \%, 0.25 \%, 0.375 \%, 0.5 \%, 0.625 \%$ y $0.75 \% \mathrm{p} / \mathrm{v})$, los cuales fueron probados por triplicado, mediante el test de difusión por disco, el cual consistió en discos impregnados de AH con los tratamientos asignados.

De igual forma estos tratamientos fueron aplicados junto con un componente de la terapia dual escogida (Amoxicilina), lo que permitió encontrar la acción de los AH al ser empleados en terapias alternativas, ya sea como antibiótico o como niveladores de pH, junto con un control positivo de inhibición con discos comerciales de Amoxicilina y de la terapia Dual.

En la aplicación de los tratamientos se observó menor crecimiento de microorganismos externos en aquellos agares que fueron tratados con AH esterilizados, evidenciando que no existe diferencia entre los diámetros de los halos de inhibición de los agares los cuales se utilizaron AH esterilizados y sin esterilizar, por esta razón se emplearon los tratamientos con AH esterilizados, para los siguiente etapa de la experimentación.

Tras una primera incubación al poseer tres tipos de microorganismos se aisló la bacteria H. Pylori por medio de pruebas microbiológicas y bioquímicas (Tinción de Gram, Ureasa, Catalasa y Oxidasa), realizando con ella una resiembra, manejada en la investigación como cepa de referencia (nativa), a fin de poder tener credibilidad y trazabilidad en los ensayos a realizar, ya que no se presenta deterioro, contaminación o mutaciones de la misma (NORMA ISO 17025, 2006).

Posteriormente se realizo la infusión de los tratamientos con AH esterilizados por ser los que presentaban menores interferencias, probando la efectividad de la acción de los AH a las concentraciones nombradas, siendo empleados en monoterapias y terapias duales, la efectividad fue dada a partir de la lectura de los halos de inhibición.

\section{Resultados y Análisis}

Debido a que los AH son hospederos de muchos microorganismos, y adicionalmente el procedimiento para la extracción de AH sin condiciones de esterilidad y los solventes empleados para su extracción que permiten la proliferación de microorganismos lo que interfiere en el análisis

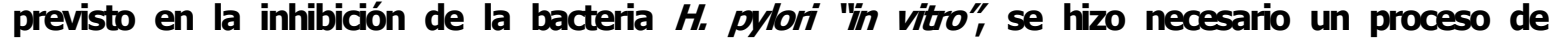
esterilización. Esto fue comprobado en los resultados obtenidos, donde se observa que aquellos agares en los que fue inoculada la bacteria y en los cuales fueron depositados sensidiscos impregnando de AH sin esterilización previa, existen otros microorganismos y hongos no identificados, que impiden una correcta visualización de los halos de inhibición, sin embargo existen placas en las cuales se puede realizar una correcta lectura del diámetro de los halos (tabla 1), por 
lo que se hace el empleo de la prueba estadística de Fisher con un nivel de confianza del $\mathbf{9 5 \%}$ determinándose la relevancia que tiene el esterilizado del sustrato del carbón.

La tabla 1 corresponde a los datos experimentales a partir de las medidas de los halos de inhibición de la bacteria $\mathbf{H}$. Pylori, en los diferentes tratamientos teniendo en auenta el proceso de esterilizado y no esterilizado de los sustratos del carbón.

Tabla 1. Medidas de los halos de inhibición con procesos de autodavados y sin autodavar

\begin{tabular}{|c|c|c|c|c|c|c|c|c|c|c|c|c|c|c|c|c|c|c|c|c|c|}
\hline & \multicolumn{3}{|c|}{$0,0625 \% \mathrm{P} / \mathrm{v}$} & \multicolumn{3}{|c|}{$0,125 \% \mathrm{P} / \mathrm{v}$} & \multicolumn{3}{|c|}{$0,25 \% \mathrm{P} / \mathrm{v}$} & \multicolumn{3}{|c|}{$0,375 \% \mathrm{P} / \mathrm{v}$} & \multicolumn{3}{|c|}{$0,5 \% \mathrm{P} / \mathrm{v}$} & \multicolumn{3}{|c|}{$0,625 \% \mathrm{P} / \mathrm{v}$} & \multicolumn{3}{|c|}{$0,75 \% \mathrm{P} / \mathrm{v}$} \\
\hline TRATAMIIENTO & 1 & 2 & 3 & 1 & 2 & 3 & 1 & 2 & 3 & 1 & 2 & 3 & 1 & 2 & 3 & 1 & 2 & 3 & 1 & 2 & 3 \\
\hline AH (Sin Autodavar) & & & & 10 & 10 & & 11 & & & 12 & & 10 & 10 & & 11 & 11 & 12 & 10 & 13 & 10 & 10 \\
\hline $\begin{array}{l}\text { AH +Amoxidilina (Sin } \\
\text { autodlavar } \\
\text { Autodavados) }\end{array}$ & 8 & & & 8 & & & 10 & & & 10 & & & 10 & & & 11 & & & 11 & & \\
\hline
\end{tabular}

Por los resultados evidenciados es de notar que el mejor tratamiento es emplear los AH esterilizados, ya que además de reducir las interferencias, los AH son muy estables frente a la destrucción por altas temperaturas es decir son poco termolábiles (ALMENDROS, GONZALEZ, \& MARTIN, 1989), además de ello el incremento de la temperatura pudo favorecer al momento de asegurar la presencia de AH, puesto que si existían impurezas de ácidos Fúlvicos estos al aumentar la temperatura, se transformaron en un polímero del tipo de los AH (ALMENDROS, GONZALEZ, \& MARTIN, 1989), lo que dio lugar a que al parecer su estructura no tuviesen mayor modificación y por ello la inhibición fuera la misma en los dos ensayos.

Al realizarse el tratamiento con los AH esterilizados a diferentes concentraciones, se obtuvieron los valores referentes a los halos de inhibición presentados en monoterapias y terapias duales (tabla 2), encontrándose que los discos impregnados con AH son capaces de impedir el crecimiento de la bacteria H.Pylori con diferente intensidad, apareciendo halos de inhibición de diámetros diferentes (figura 3) lo que permitió detectar en cuales concentraciones tuvo mayor actividad los AH como terapia altemativa o complemento de la terapia dual escogida (Amoxicilina + AH), contra el crecimiento de la bacteria.

Relación de datos experimentales entorno a la inhibición de la bacteria $\boldsymbol{H}$. Pylori frente a los diferentes tratamientos utilizados para probar los AH esterilizados de acuerdo a los tratamientos, monoterapias (AH) a siete concentraciones: 0,0625\%, 0,125\%, 0,25\%, 0,375\%, 0,5\%, 0,625\% $0,75 \%$ y terapia dual (AH+ Amoxicilina).

Tabla 2. Halos de inhibición con tratamientos con AH Esterilizados.

\begin{tabular}{|c|c|c|c|c|c|c|c|c|c|c|c|c|c|c|c|c|c|c|c|c|c|c|}
\hline & & \multicolumn{3}{|c|}{$\begin{array}{c}0,0625 \% \\
\text { P/v }\end{array}$} & \multicolumn{3}{|c|}{$0,125 \% \mathrm{P} / \mathrm{v}$} & \multicolumn{3}{|c|}{$0,25 \% \mathrm{P} / \mathrm{v}$} & \multicolumn{3}{|c|}{$\begin{array}{c}0,375 \% \\
P / v\end{array}$} & \multicolumn{3}{|c|}{$0,5 \% \mathrm{P} / \mathrm{v}$} & \multicolumn{3}{|c|}{$0,625 \% \mathrm{P} / \mathrm{v}$} & \multicolumn{3}{|c|}{$0,75 \% \mathrm{P} / \mathrm{v}$} \\
\hline $\begin{array}{c}\text { CULTIVO } \\
\text { REALIZADO }\end{array}$ & TRATAMIENTO & 1 & 2 & 3 & 1 & 2 & 3 & 1 & 2 & 3 & 1 & 2 & 3 & 1 & 2 & 3 & 1 & 2 & 3 & 1 & 2 & 3 \\
\hline RESIEMBRA & AH (mm) & 7 & 6 & 6 & 13 & 14 & 13 & 16 & 15 & 16 & 17 & 17 & 16 & 18 & 16 & 17 & 18 & 17 & 17 & 18 & 18 & 19 \\
\hline $\begin{array}{c}\text { DE LA } \\
\text { BIOPSIA }\end{array}$ & $\begin{array}{c}\text { AH + } \\
\text { MEDICAMENTO } \\
(\mathbf{m m})\end{array}$ & & & 10 & 11 & 10 & 11 & 11 & 11 & 9 & 11 & 10 & 12 & 11 & 11 & 11 & 13 & 12 & 12 & 14 & 13 & 13 \\
\hline
\end{tabular}

La tabla 3 muestra los resultados obtenidos en cuanto a los tratamientos empleados como control negativo, los cuales son reconocidos como sensibles a la inhibición de la H.pylori. 
Tabla 3. Halos de inhibición presentados en el control negativo con Amoxicilina.

\begin{tabular}{|l|c|c|c|}
\hline \multicolumn{1}{|c|}{$\begin{array}{c}\text { TRATAMIENTO } \\
\text { (Control negativo } C_{1} \text { ) }\end{array}$} & Ensayo 1 & Ensayo 2 & Ensayo 3 \\
\hline AMOXICILINA & $17 \mathrm{~mm}$ & $17 \mathrm{~mm}$ & $17 \mathrm{~mm}$ \\
\hline $\begin{array}{l}\text { Terapia dual } \\
\text { (amoxicilina + omeprazol) }\end{array}$ & $20 \mathrm{~mm}$ & $20 \mathrm{~mm}$ & $20 \mathrm{~mm}$ \\
\hline
\end{tabular}

Para realizar la interpretación de los halos de inhibición y conocer la actividad desarrollada de las diferentes concentraciones del sustrato del carbón, frente a la $H$. Pylori se realizo el análisis conforme a las categonías propuestas por (MONKS R, 2002), las cuales dependiendo del tamaño del diámetro de los halos, presenta diferentes actividades:

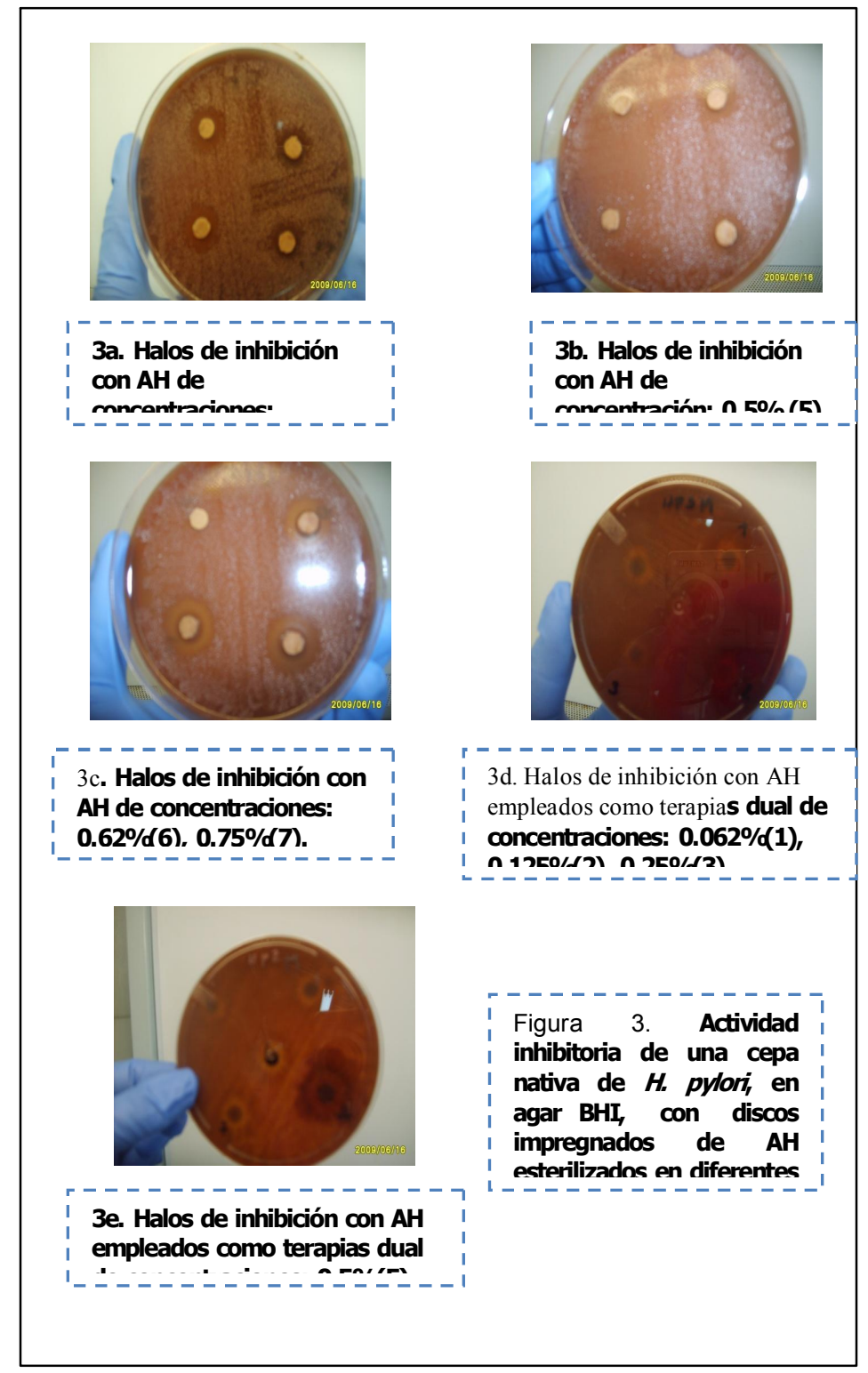

(-) No hay actividad

(+) Actividad leve o débil (diámetro entre $7-11 \mathrm{~mm}$ )

(++) Actividad moderada (diámetro entre 11-16mm)

(+++) Actividad fuerte (diámetro mayor a $16 \mathrm{~mm}$ ) 
Los AH por ser un sustrato del cual no se conoce su completa composición y no encontrarse referenciado como antibiótico, sus halos de inhibición no pueden ser interpretados por Tablas NCCLS (Comité Nacional de Estándares de Laboratorio Clínico) para ser informado como susceptible, intermedio ó resistente (Andréis), tan solo se realizó la comparación con el diámetro de la zona inhibida "Amoxicilina" (tabla 3), donde su diámetro de inhibición es reconocido por la NCCLS.

Con respecto a lo descrito en la figura $3 a$, se encontró que la concentración $0.0625 \%(1)$, presenta un promedio en los halos de inhibición $6.33 \mathrm{~mm} \pm 0.55$, lo que quiere decir que se encuentra en una actividad nula o muy débil frente a las categorías tomadas para la interpretación. De igual forma el diámetro de inhibición de la concentración $0.125 \%$ (2) (tabla 2), presenta una actividad moderada, ya que halos obtenidos son aproximadamente $13.33 \mathrm{~mm} \pm 0.57$, lo que permite mencionar que aunque esta concentración es una de las más bajas utilizadas en la inhibición de la bacteria, se observa el desarrollo de halos grandes, aunque si lo correlacionamos a Amoxicilina (tabla 3), manejado como control positivo, esta concentración de AH no puede ser categorizada como antibiótico sensible. En cuanto a la concentración $0.25 \%(3)$, se puede ver la especial disminución de la intensidad de crecimiento de $\boldsymbol{H}$. pylori alrededor de los discos, comparado con las anteriores concentraciones (figura 3a), puesto que sus diámetros de inhibición ascienden en gran medida, tomando un valor promedio de $15.66 \mathrm{~mm} \pm 0.57$, lo que permite establecer que la actividad de sustrato es moderadamente alta acercándose a la inhibición dada por la Amoxicilina.

Para el caso espećfico de la concentración $0.375 \%$ se puede definir que tiene tendencia a desarrollar una actividad fuerte, ya que el diámetro promedio de los halos de inhibición es de 16.66 mm \pm 0.57 . La acción ejercida por esta concentración puede ser comparada con la que ejerce la Amoxicilina, lo que lleva a decir que desde esta concentración los AH asumen una inhibición muy fuerte contra la bacteria $\boldsymbol{H}$. pylori.

Teniendo en auenta los halos de inhibición de las concentraciones $0.5 \%(5), 0.625 \%(6)$ y $0.75 \%$ (7), los cuales presentan promedios de $17.0 \mathrm{~mm} \pm 1,17.33 \mathrm{~mm} \pm 0.57,18.33 \mathrm{~mm} \pm 0.57$ respectivamente, se puede observar (figura $3 b$ y $3 c$ ) que el tamaño de los diámetros aumento considerablemente, catalogando la actividad de los AH en estas concentraciones como fuerte, acorde con el análisis.

Al hacer la comparación de los AH con respecto a la Amoxicilina, la cual presenta halos de inhibición de $17 \mathrm{~mm}$ (medida catalogada como sensible según la NCCLS), por lo que los AH a estas concentraciones presentan una fuerte actividad antibacteriana "in vitro" y podrían entrar a formar parte de la categoría de sensible, puesto que algunos de los compuestos presentes en los AH son capaces de inhibir el crecimiento de $\boldsymbol{H}$. pylori conforme a como lo realiza la Amoxicilina.

Teniendo en cuenta cada una de las concentraciones y tratamientos establecidos acorde a la experimentación con los AH, a partir de los resultados obtenidos se determina la acción que ejercen los AH extraídos a partir del carbón Leonardítico colombiano en la inhibición de la bacteria $H_{\text {. pylori }}$ "in vitro", muestran que este sustrato del carbón ejerce una función bactericida y antibiótica, realizados por medio de procesos bioquímicos y fisicoquímicos, esto se debe a que la macromolécula de los AH, le da diversidad de propiedades biológicas, llevando a cabo mecanismos de acción, dados por los grupos funcionales que presenta la estructura, entre los se puede resaltar la acción ejercida por los grupos amina, amida e hidroxilo, interviniendo posiblemente en la permeabilidad, elongación y síntesis de proteínas, la función ejercida por los iones carboxilato al actuar como surfactante, dando lugar a ruptura de la barrera de lípidos y solubilización de proteínas, así como la alteración de la bicapa lipídica, shock osmótico llevando a la perdida de iones, causado por los péptidos. 
Interpretando los resultados dados en la actividad ejercida por la terapia dual, se observa que esta resulta ser menos efectiva que la monoterapia, puesto que los diámetros de los halos inhibición presentan una disminución de 2 a $5 \mathrm{~mm}$ aproximadamente, en comparación con los discos trabajados únicamente como monoterapia (tabla 2), lo que es corroborado con la prueba estadística t-Student.

La razón por la que la terapia dual tuvo menor inhibición que la monoterapia, pudo deberse a que se genero un antagonismo competitivo irreversible, por lo aul los dos compuestos compitieron por el mismo receptor, en este caso posiblemente podría tratarse de la proteína ligadora de la penicilina (PBP) (Elergonomista).

Al determinar que los AH ejercen una función más efectiva al ser empleados como monoterapia, los resultados obtenidos fueron comparados con la terapia dual escogida como punto de referencia ( Amoxicilina + Omeprazol), encontrándose que son de menor diámetro (aproximadamente 4mm), comparados con aquellos halos generados por los discos impregnados únicamente por los AH rango entre $17 \mathrm{~mm}-19 \mathrm{~mm}$, para aquellos que resultaron con una actividad fuerte, (figura 3d), lo que nos permite aseverar que los AH son más efectivos al emplearlos como monoterapia, llevando a que se le puedan atribuir funciones tales como antibiótica y regulador de $\mathrm{pH}$, impidiendo la supenvivencia de la $\boldsymbol{H}$. Pylori, dada por la presencia de grupos funcionales carboxílicos, los auales dan la capacidad a las moléculas AH de formar quelatos multivalentes con el níquel (cofactor relevante para activación de la enzima ureasa), lo que impide la fijación y crecimiento de la bacteria, interviniendo como agentes activos que modifican reacciones bioquímicas. Además de ello los AH se le pueden atribuir propiedades como nivelador de acidez, puesto que aumentan el pH del medio, probablemente por estar diluidos en medio básico impidiendo así la activación de la ureasa, al igual por ser ácidos orgánicos polibásicos con un pH cerca de 8-9 (ROMERA PEREZ \& GUERRERO).

\section{Conclusiones}

Con este tipo de investigaciones se logra que el ejercicio docente evolucione en sus prácticas educativas, lo que permitirá promover una actitud investigativa en el estudiante al aplicar, relacionar, comparar, los conceptos vistos en clase, siendo capaces de inferir y actuar responsablemente con criterios cient́ficos en contextos reales tales como la necesidad de remediación de diferentes enfermedades que aquejan a la humanidad como lo es las causadas por la H.Pylori.

Esta investigación puede incentivar en los estudiantes el empleo de las sustancias naturales (AH extraídos de una fuente natural como lo es el Carbón Leonarditico colombiano) en mejorar la calidad de vida, lo que permitirá mostrarles la aplicación de las ciencias en la cotidianidad.

Enseñar la química desde diferentes perspectivas desde un marco pragmático permite que los estudiantes tengan una visión más amplia en tomo a la disciplina, que les ayude a desenvolverse en problemas de la cotidianidad a partir de los conocimientos obtenidos.

Realizar investigaciones en ciencia permite que los docentes cumplan un rol polifacético en la sociedad, haciendo que el ejercicio docente se convierta en una labor que no solo se lleve a cabo en las aulas de dase si no que trascienda al campo disciplinar. 


\section{Bibliografía}

Andréis, I. d. (s.f.). Proyecto piloto de prospección de biactividad en organismos marinos colombianos. Recuperado el 25 de Junio de 2009, de IVERMAR:

http: //Www.invemar.org.co/redcostera1/invemar/docs/2098MbioactividadEsponjas. pdf

Almendros, G., Gonzalez, J. F., \& Martin, F. (1989). Alteraciones del Humus en Bosques Mediterráneos Continentales Afectados por Incendios. Recuperado el 28 de Agosto de 2009, de Opcion Meditenaneennes: http: //ressources.ciheam.org/om/pdf/a03/CI000513.pdf

Bruce, E., Dunn, N., Hartley, C y Blaser, MJ. (1997). Helicobacter pylori. Clinical Microbiology Reviens, 10(4), p720-74.

Canosa, J. (1980). Helicobacter Pylori; Detección e incidencia. Recuperado el 17 de Diciembre de 2008, de G.E.R.NE.CE.: http: //uww.aaed.org.ar/uww.aaed.org.ar/gemece/pylori.htm

Conicet. (s.f.). Diccionario de Lombriaultura: Acido húmico, A.H. Obtenido de Manual de lombricultura: http://www.manualdelombricultura.com/glosario/pal/114.html

Corpbercor Cia. Ltda. (s.f.). ACIDO HUMICO. Reauperado el 16 de Julio de 2009, de http://venezuela.acambiode.com/producto_76545505355586254556318007086477.html

Elergonomista. (s.f.). Mecanismo de acción de un fármaco. Receptores. Recuperado el 2 de Julio de 2009, de Farmacología: http://www.elergonomista.com/farmacologia/fd04.htm

Fosac. (5 de Julio de 2005). Importancia De Los Ácidos Humicos Mo-Std. Recuperado el 20 de Diciembre de 2008, de FOSAC: http://fosacperu.blogspot.com/2007/07/importancia-de-los-cidoshumicos-del-mo.html

Guedea Fernandez, G. (1 de Junio de 2007). Tincion de Gram Recuperado el 15 de Julio de 2009, de Revista de ciencias: http://uww.revistaciencias.com/publicaciones/EElpZEVkykPMncqxmd.php

Hoffmann, M., Yost, E., Eisenreich, S., \& Maier, W. (1981). Characterization of Soluble and Colloidal-Phase Metal-Complexes in River Water by Ultrafiltration - a Mass-Balance Approach. Revista Internacional Environmental Science \& Technology.

HumicHealth.info. (1998). Statements from Researchers About the Anti - Viral Efficacy of Humic Acid. Recuperado el 10 de Diciembre de 2008, de HumicHealth.info: http: //uww.humichealth.info/statements.htm

$\begin{array}{llllll}\text { Humifulvate } R x & \text { (s.f.). Recuperado el } 5 \text { de Diciembre de 2008, de }\end{array}$ http: //www.enerex.ca/espanol/productos/humifulvate__x.htm

Kononova, M (1982). Materia orgánica del suelo su naturaleza, propiedades y métodos de investigación. Barcelona: Oikos S.A.

Levi, E., \& Pineda, R. (1996). Extracción de AH a partir de carbón bituminosa alto volátil A. Tesis de pregrado . Universidad Distrital Francisco José De Caldas, Facultad De Ciencias Y Educación.

Lopez, M. (1995). Helicobacter Pylori, microbiología, dínica y tratamiento. Barcelona: División Iberoamericana. 
Mikkelsen R, L (2005). Humic Materials for Agriculture. Better Crops with Plant Food. California Department of Food and Agriaulture (CDFA). 89, 6-10.

Monks R., C. L. (2002). Anticancer, antichemotactic and antimicrobial activities of manine sponges collected off the coast of Santa Catarina, southem Brazil. Journal of Experimental Marine Biology and Ecology (281), 1-12.

NORMA ISO 17025. (14 de Octubre de 2006). Explicaciones sobre los aultivos de referencia según la ISO 17025. Recuperado el 18 de Julio de 2009, de WIKILEARNING: http://(4)http//uww.wikilearning.com/articulo/explicaciones_sobre_los_cultivos_de_referencia_seg un_la_iso_17025-

Romera Perez, M. d., \& GUERRERO, L (s.f.). Importancia de la materia orgánica en la Agricultura Ecológica Recuperado el 28 de Agosto de 2009, de Canalagro: http://servicios.ideal.es/canalagro/datos/agricultura_ecologica/agricultura_ecologica14.htm

Sierra, F., \& Torres, D. (2001). Helicobacter pylori; El holocausto Revolucionario. Colombia: Ediciones Médicas Latinoamericanas S.A.

Valsecia, M. (s.f.). Farmacodinamia. Recuperado el 13 de Julio de 2009, de http: //uww.med.unne.edu.ar/catedras/farmacologia/clas2do/fardinam.pdf 